\title{
COMPOSIÇÃO CENTESIMAL E DE MINERAIS DE CASCA E POLPA DE MANGA (Mangifera indica L.) CV. TOMMY ATKINS ${ }^{1}$
}

\author{
ADRIANA MARQUES ${ }^{2}$, GUSTAVO CHICAYBAM ${ }^{3}$, MARIANA TARANTO ARAUJO ${ }^{4}$, \\ LUCIANA RIBEIRO TRAJANO MANHÃES ${ }^{5}$, ARMANDO UBIRAJARA OLIVEIRA SABAA-SRUR ${ }^{6}$
}

RESUMO-O Brasil produz cerca de 140 milhões de toneladas de alimento por ano; entretanto, a fome ainda é um dos maiores problemas enfrentados por grande parte da sua população. $\mathrm{O}$ aproveitamento integral de alimentos é uma alternativa para suprir as necessidades nutricionais e contribuir para reduzir o lixo orgânico. Nesse sentido, cascas, talos, sementes e outras partes, tradicionalmente não utilizadas como alimentos, podem ser incorporadas na dieta alimentar. Estudos revelam que cascas de muitas hortifrutícolas possuem mais nutrientes que determinadas polpas, a parte tradicionalmente consumida. No entanto, o conhecimento sobre a concentração de metais pesados nessas frações também é importante, uma vez que podem provocar intoxicações alimentares, se consumidos, mesmo em concentrações reduzidas. O Brasil é o sétimo produtor mundial de manga e dentre as cultivares de importância comercial, a cv. Tommy Atkins é a mais plantada e exportada pelo Brasil. A pesquisa teve como objetivo determinar a composição centesimal e o perfil de macro e microminerais, inclusive, os elementos-traço, da casca e da polpa de manga cv. Tommy Atkins. A maior fração da composição centesimal da casca estudada foi a umidade, seguida dos carboidratos totais, com destaque para o teor de fibra alimentar total (FAT), que representou cerca $11 \%$ dessa quantidade. Já os teores de proteína e de cinzas apresentaram cerca de $2,5 \%$, enquanto a fração lipídica foi inferior aos demais componentes. O perfil de minerais da casca revelou que as concentrações desses elementos foram superiores aos encontrados na polpa, exceto para zinco e ferro. As concentrações de metais pesados presentes na casca, em função das concentrações menores que $0,1 \mathrm{mg} / 100 \mathrm{~g}$, possibilitam a sua utilização na alimentação humana. A composição centesimal e o perfil mineral da casca da manga demonstraram a sua importância nutricional e a possibilidade da utilização dessa parte, até então considerada não comestível na dieta brasileira, visando a contribuir para a melhora do estado nutricional da população e a reduzir os resíduos do processo industrial. Termos para Indexação: casca de manga, composição centesimal, perfil de minerais.

\section{MANGO RIND AND PULP (Mangifera indica L.) CV. TOMMY ATKINS CENTESIMAL COMPOSITION AND MINERALS CONTENTS}

ABSTRACT - Brazil produces about 140 million tons of food per year, however, the hunger is one of the biggest problems faced for great part of its population. The integral food exploitation is an alternative to supply the nutrition necessities of this population pursuing and to contribute to reduce the organic waste. In this direction, rind, stems, seeds and other parts traditionally not used as foods can be incorporated in the alimentary diet. Studies have verified that rind of many fruits and vegetable possess more nutrient than the pulp, the available part. However, the knowledge of the heavy metal concentration in these fractions also becomes important, as these can provoke alimentary poisonings, even when are consumed in low concentrations. Brazil is the seventh greater worldwide mango producer and the main planted and exported variety is Tommy Atkins. The objective of this research was to determine the percent composition and the mineral profile of the macro and micro minerals, including heavy metals of the rind of Tommy Atkins mango. The biggest fraction of the percent composition of the rind was the moisture, followed of the total carbohydrates, with a proeminent level of total dietary fiber (TDF) that represented around $11 \%$ of this amount. The ashes and protein levels presented about $2.5 \%$, while the lipid fraction was inferior in relation to other component. The mineral profile of the rind showed that the concentrations of these elements are superior from the one found in the pulp, except for zinc and iron. The low heavy metal concentrations found in the rind make possible its use in the human dietary. The percent composition and mineral profile of the rind had showed its nutritional importance and the possibility of the use of this parts, considered not edible in the Brazilian diet and could contribute for improvement of the nutrition situation of the population and to reduce the residues of the industry processing.

Index terms: mango rind, centesimal composition, mineral contents.

\footnotetext{
1(Trabalho 202-09). Recebido em: 24-08-2009. Aceito para publicação em: 02-03-2010.

${ }^{2}$ Técnica em Alimentos (IFRJ), Graduanda do Curso de Nutrição da Universidade Veiga de Almeida (UVA) - Rio de Janeiro-RJ, adrianamarquesuva@yahoo.com.br

${ }^{3}$ Graduando do Curso de Nutrição da UVA - gustavo.chicaybam@yahoo.com.br

${ }^{4}$ Nutricionista/ UVA -maritaranto01@gmail.com

${ }^{5}$ Msc. Ciência e Tecnologia de Alimentos, Prof. Assistente do Curso de Nutrição/UVA -lucianartmanhaes@gmail.com

${ }^{6}$ Dr. Ciência dos Alimentos, Prof. Adjunto do Instituto de Nutrição Josué de Castro (UFRJ) - Rio de Janeiro - RJ - sabaasrur@yahoo.com.br
} 


\section{INTRODUÇÃO}

Apesar de o Brasil produzir cerca de 140 milhões de toneladas de alimento por ano, a fome ainda é um dos seus maiores problemas (GONDIM et al., 2005). Bastante contraditório a esse quadro de fome é a prática do desperdício, muito comum na cultura brasileira. $\mathrm{O}$ aproveitamento integral de alimentos é uma alternativa para suprir as necessidades nutricionais, agregar valores no agronegócio e para reduzir o lixo orgânico (OLIVEIRA et al., 2002).

Estudos mostram que, de forma geral, as cascas de frutas possuem mais nutrientes que as polpas, consideradas a porção não comestível (GONDIM et al., 2005; CÓRDOVA et al., 2005). Para que se tenha um aporte adequado de macro e micronutrientes, conforme a Ingestão Diária Recomendada (IDR), faz-se necessária a determinação do valor nutricional dessas frações, as cascas, e das polpas (GONDIM et al., 2005). No entanto, outro fator que deve ser considerado no que tange ao uso das partes tradicionalmente não utilizadas na alimentação, é a possível presença de compostos tóxicos nesses resíduos, que podem ocasionar risco à saúde humana, provocando intoxicações alimentares, mesmo que consumidos em concentrações reduzidas (SOARES, 2004; ROCHA et al., 1985). Metais pesados e agrotóxicos podem ser considerados como responsáveis por esses riscos. A constituição do solo onde são cultivadas as frutas e hortaliças, e o uso adequado de fertilizantes devem ser considerados. O uso de defensivos deve ser feito com cuidado, e os prazos respeitados, já que podem facilmente contaminar frutas e hortaliças se utilizados de maneira inadequada, estando as cascas e os talos, respectivamente, em maior contato com esses produtos (COSTA et al., 2001).

O Brasil é o sétimo produtor mundial de manga e, dentre as cultivares de importância comercial, a Tommy Atkins é a mais plantada e exportada pelo Brasil (FRANCO et al., 2004). No processo industrial dessa matéria-prima, cascas e caroços são desprezados e correspondem acerca de $16,0 \%$ do fruto (CARVALHO et al., 2004). Alguns trabalhos avaliaram os aspectos sensoriais de preparações à base de cascas de frutas e demonstraram ótima aceitabilidade quando comparadas às preparações tradicionais à base de polpa (OLIVEIRA et al., 2002; LIRA FILHO, 1995). Portanto, este trabalho teve como objetivo determinar a composição centesimal, o conteúdo de minerais e metais pesados presentes na casca e na polpa de manga Tommy Atkins.

\section{MATERIAIS E MÉTODOS}

Mangas cv. Tommy Atkins no estádio de maturação próprio para consumo foram adquiridas no mercado do Município do Rio de Janeiro - RJ, e transportadas para o Laboratório de Análise de Alimentos (LAA) da Universidade Veiga de Almeida (UVA). As frutas foram lavadas em água corrente, a polpa foi separada das cascas manualmente com auxílio de facas higienizadas. Em seguida, essas porções, separadamente, foram acondicionadas em sacos de polietileno e armazenadas sob refrigeração até o momento das análises $\left(5^{\circ} \mathrm{C} \pm 2^{\circ} \mathrm{C}\right)$.

$\mathrm{O}$ teor de umidade de ambas as frações foi determinado pela secagem em estufa a $105^{\circ} \mathrm{C}$ (IAL, 2005), o resíduo mineral fixo por incineração em mufla a $550^{\circ} \mathrm{C}$ (IAL, 2005), a fração lipídica pelo método de Soxhlet (IAL, 2005). O nitrogênio total (Nt) foi determinado pelo método de Kjeldahl, e o teor de proteína bruta, multiplicando-se o teor de $\mathrm{Nt}$ pelo fator de conversão 6,25 (AOAC, 1995). O teor de glicídeos redutores, não redutores e amido foram determinados pelo método espectofotométrico de Somogy adaptado por Nelson (1944). O teor de fibra alimentar total (FAT) foi determinado pelo método gravimétrico não enzimático (LI; CARDOZO, 1994). O teor de carboidratos totais foi obtido pelo somatório dos glicídeos redutores, não redutores, amido e FAT. A determinação do perfil de minerais da casca e da polpa foi realizada após calcinação de amostras em mufla a $550^{\circ} \mathrm{C}$, por período mínimo de 2 horas. As cinzas obtidas foram dissolvidas em $\mathrm{HCl} 2 \mathrm{~mol} / \mathrm{L}$. Então foram analisadas por espectrometria de massa com plasma indutivamente acoplado no modo semiquantitativo, utilizando o equipamento ELAN 6000 da Perkin Elmer-Sciex (AOAC, 1995). Todas as determinações foram realizadas com três repetições expressas em média aritmética e em miligramas de mineral correspondente $/ 100 \mathrm{~g}$ de amostra.

\section{RESULTADOS E DISCUSSÃO}

Informações sobre a composição nutricional de alimentos no Brasil são escassas, principalmente de partes tradicionalmente não comestíveis de matérias-primas, tais como cascas e sementes, tornando-se importante a realização desta pesquisa neste contexto.

A população brasileira não possui o hábito de consumir partes não comestíveis de frutas e hortaliças, descartando-as e desperdiçando quantidades consideráveis de nutrientes, o que torna cada vez mais importante o incentivo à inclusão dessas porções na alimentação humana (GONDIM et al., 
2005; MARQUES et al., 2008). Essas informações são reforçadas por Nogueira et al. (2007), que verificaram altas concentrações de minerais em bagaços oriundos da industrialização de sucos de frutas. Em relação à manga, não foram encontrados, na literatura, dados a respeito da composição centesimal da parte não comestível dessa fruta, em especial da casca.

A composição centesimal das cascas da manga revelou a sua importância nutricional e a possibilidade da utilização dessa parte, até então considerada não comestível, na dieta brasileira, visando a contribuir para a melhora do estado nutricional da população e a reduzir os problemas causados pela desnutrição no Brasil, além de reduzir o acúmulo de lixos orgânicos produzidos no País. A Tabela 1 apresenta os resultados médios das determinações dos constituintes da composição centesimal das cascas e de polpa de manga, revelando que esse resíduo pode ser considerado uma importante fonte de substâncias orgânicas, como proteínas, carboidratos e fibras, além de elementos minerais. O maior constituinte da composição centesimal da casca foi a umidade, que correspondeu a $78,70 \% \pm 0,45$, podendo contribuir para a perecibilidade do fruto depois de colhido e se manuseado inadequadamente. Teores semelhantes podem ser encontrados na maioria das cascas de muitos vegetais que apresentam textura parecida com esse fruto, como o abacate, que apresenta aproximadamente $76,95 \%$ de umidade (GONDIM et al., 2005). A comparação da composição centesimal da casca e da polpa da manga revelou que os teores de umidade entre essas frações do fruto foram semelhantes. A segunda maior fração presente na casca foi de carboidratos totais, com destaque para a FAT, que representou cerca de $11 \%$, sendo superior ao encontrado na polpa (Tabela 1), perfeitamente justificado, já que epicarpos de frutos são constituídos de celulose, lignina e algumas hemiceluloses, principais constituintes da fibra insolúvel (FI) de um alimento. As frações proteicas, minerais e lipídicas, juntas, representam cerca de $2,5 \%$ e completaram a composição centesimal da casca tradicionalmente não utilizada na alimentação. Quando comparada com a polpa, essas frações foram superiores (tabela 1) cerca de três vezes. Merece destaque, nesse resíduo, a fração lipídica que foi inferior aos outros constituintes, embora, tradicionalmente, as frações residuais de frutos, como cascas e sementes ou caroços, concentrem elevados teores de lipídeos (GONDIM et al., 2005).

Em relação às fibras na alimentação, a American Dietetic Association recomenda uma ingestão diária para adultos de 20 a $30 \mathrm{~g}$ para uma dieta rica em carboidratos e baixa em gorduras (ADA, 1993).
Além de conter cerca de 4 vezes mais FAT que a polpa, $100 \mathrm{~g}$ de casca de manga atende em torno de $50 \%$ dessa recomendação, podendo então contribuir na prevenção de doenças cardiovasculares e redução dos níveis séricos de glicose e lipídeos.

A casca de manga revelou ser uma importante fonte de elementos minerais (Tabela 2), que exercem funções essenciais no organismo, como íons dissolvidos em fluidos corpóreos, que regulam as atividades de muitas enzimas, mantêm o equilíbrio ácido-base e a pressão osmótica (ANDRADE et al., 2003). Os resultados das determinações realizadas nessas cascas mostraram que as concentrações desses elementos foram superiores às encontradas na polpa, exceto para zinco e ferro (Tabela 2). O mineral que apresentou maior concentração na casca foi o potássio $(176,05 \mathrm{mg} / 100 \mathrm{~g})$, importante regulador da atividade neuromuscular, como, por exemplo, a fadiga, fraqueza e cãibras, e promoção do crescimento celular, seguido de cálcio $(74,06 \mathrm{mg} / 100 \mathrm{~g})$ e magnésio $(22,38 \mathrm{mg} / 100 \mathrm{~g})$, que atuam em conjunto em atividades hormonais vitais ao organismo. A deficiência desses minerais pode provocar osteoporose em adultos e até raquitismo em crianças (SHILS et al., 2003). O teor de sódio encontrado foi de $37,47 \mathrm{mg} / 100 \mathrm{~g}$ de casca, e embora não possua referências de IDR a respeito desse mineral, já se sabe sua importante atuação no controle da absorção e transporte de alguns nutrientes, como cloro, aminoácidos, glicose e água, além da importante bomba $\mathrm{Na} / \mathrm{K}$ (CARDOSO, 2006).

Os metais pesados presentes na casca em concentrações menores que $0,1 \mathrm{mg} / 100 \mathrm{~g}$ de casca (Tabela 3), indica confiabilidade na utilização dessas cascas em diversas preparações, sendo descartado o risco de intoxicação por esses elementos. Outro dado importante é que, quando esses teores são comparados com os encontrados na polpa, mostramse bem inferiores. 
TABELA 1- Composição centesimal da casca e da polpa de manga (g/100g).

\begin{tabular}{lcc}
\hline Componentes & Casca da manga $^{*}$ & Polpa da manga $^{*}$ \\
\hline Umidade & $78,70 \pm 0,45$ & $82,11 \pm 0,21$ \\
Resíduo Mineral Fixo & $0,99 \pm 0,05$ & $0,34 \pm 0,06$ \\
Lipídeos & $0,18 \pm 0,01$ & $0,61 \pm 0,03$ \\
Proteínas & $1,24 \pm 0,11$ & $0,44 \pm 0,08$ \\
Açúcares Redutores & $0,55 \pm 0,02$ & $4,13 \pm 0,12$ \\
Açúcares não redutores & $1,69 \pm 0,04$ & $8,94 \pm 0,17$ \\
Amido & $0,19 \pm 0,13$ & $0,15 \pm 0,16$ \\
Fibra Alimentar Total (FAT) & $11,02 \pm 0,07$ & $3,28 \pm 0,28$ \\
Carboidratos totais & 12,89 & 16,5 \\
\hline
\end{tabular}

* Média \pm Desvio-Padrão

TABELA 2 - Teor de minerais da casca e da polpa de manga Tommy (mg/100g).

\begin{tabular}{cccccccc}
\hline Componentes & Magnésio & Fósforo & Ferro & Sódio & Potássio & Zinco & Cálcio \\
\hline Casca $^{*}$ & 22,38 & 17,53 & $\operatorname{Tr}$ & 37,47 & 176,05 & $\operatorname{Tr}$ & 74,06 \\
Polpa $^{*}$ & 7 & 14 & 0,1 & $\operatorname{Tr}$ & 138 & 0,1 & 8 \\
\hline
\end{tabular}

* Média aritmética

$\operatorname{Tr}-\operatorname{Traços}$

TABELA 3 - Teor de metais pesados da casca e da polpa de manga Tommy (mg/100g).

\begin{tabular}{ccccccc}
\hline Componentes & Chumbo & Cobre & Vanádio & Cobalto & Níquel & Manganês \\
\hline Casca $^{*}$ & $<0,1$ & $<0,1$ & $<0,1$ & $<0,1$ & $<0,1$ & $<0,1$ \\
Polpa $^{*}$ & - & 0,6 & - & - & - & 0,34 \\
\hline
\end{tabular}

* Média \pm aritmética

\section{CONCLUSÃO}

1-Os conteúdos de proteína, amido e fibra alimentar da casca são maiores do que na polpa. Os teores de Magnésio, Fósforo, Sódio, Potássio e Cálcio são maiores para a porção da casca do que para polpa. As cascas apresentam baixas concentrações de metais pesados.

2-Por tratar-se de porção tradicionalmente não utilizada na alimentação, sugerem-se pesquisas para determinar a composição de outros nutrientes, como as vitaminas, verificando a biodisponibilidade desses micronutrientes no organismo humano e desenvolvendo tecnologias que facilitem a utilização dessa matéria-prima em produtos alimentícios.

\section{REFERÊNCIAS}

ADA - AMERICAN DIETETIC ASSOCIATION. Position of the American Dietetic Association: Health Implications of Dietary Fiber. Journal of the American Dietetic Associacion, Chicago, v. 93, p. 1446-1447, 1993.

ANDRADE, E.C.B.; BARROS, A.M.; TAKASE, I. Avaliação da solubilidade de cobre e zinco em caldos de leguminosas. Ciência e Tecnologia de Alimentos, Campinas, v.3, n3, p.386-388, 2003.

AOAC - ASSOCIATION OF OFFICIAL ANALYTICAL CHEMISTS. Official methods of analysis of the Association of Official Analysis Chemists. Arlington, 1995, p. 957.

CARDOSO, M. A. Nutrição Humana: nutrição e metabolismo. Rio de Janeiro: Guanabara Koogan, 2006. 
CARVALHO, C. R. L.; ROSSETTO, C. J.; MANTOVANI, D. M. B.; MORGANO, M. A.; CASTRO, J. V.; BORTOLETTO, N. Avaliação de cultivares de mangueira selecionadas pelo Instituto Agronômico de Campinas comparadas a outras de importância comercial. Revista Brasileira de Fruticultura, Jaboticabal, v. 26, n. 2, p. 264-271, 2004.

CÓRDOVA, K.R.V.; GAMA, T.M.M.T.B.; WINTER, C.M.G.; NETO, G.K.; FREITAS, R.J.S. Características físico-químicas da casca do maracujá-amarelo (Passiflora edulis Flavicarpa Degener) obtidas por secagem. BoletimCEPPA, Curitiba, v. 23, n. 2, 2005.

COSTA, C.A.; CASALI, V.W.D.; RUIZ, H.A.; JORDÃO, C.P.; CECON, P.R. Teor de metais pesados e produção de alface adubada com composto de lixo urbano. Horticultura Brasileira, Brasília, v. $19 \mathrm{n}$. 01, p. 10-16, 2001.

FRANCO, M.R.B.; RODRIGUEZ-AMAYA, D.; LANÇAS, F.M. Compostos Voláteis de Três Cultivares de Manga (Mangifera indica L.). Ciência Tecnologia de Alimentos, Campinas, v.24, n.2, p. 165-169, 2004.

GONDIM, A. M.; MOURA, V. M. F.; DANTAS, S.A.; MEDEIROS, R. L. S.; SANTOS, K. M. Composição Centesimal e de minerais em cascas de frutas. Ciência Tecnologia de Alimentos, Campinas, v.25, n.4, p.825-827, 2005.

INSTITUTO ADOLFO LUTZ- Normas analíticas do Instituto Adolf Lutz: métodos químicos e físicos para análise de alimentos. 4.ed. Brasília: Ministério da Saúde, 2005. p.1018.

LI, B.W.; CARDOZO, M.S. Nonenzymaticgravimetric determination o dietary fiber in fruits and vegetables. Journal of AOAC Internationl, Arlington, v.77, n.3, p.687-689, 1994.

LIRA FILHO, J.F. Utilização da casca do maracujá-amarelo (Passiflora edulis, f. Flavicarpa Degener) na produção de geleia, 1995. $131 \mathrm{f}$. Dissertação (Mestre em Tecnologia de Alimentos) - Faculdade de Engenharia de Alimentos, Universidade Estadual de Campinas Campinas, 1995.
MARQUES, A. P. S.; CHICAYBAM, G.; TARANTO, M.; MANHÃES, L. R. T. Comparação da composição centesimal da casca de manga Tommy (Mangifera indica L) e da casca de melancia (Citrullus lanatus) com suas respectivas polpas. Revista da Associação Brasileira de Nutrição, Rio de Janeiro, v.1, n.1, p. 100-100, 2008.

NELSON, N. A fotometric adaptation of Somogy method for the determination of glucose. Journal Biological Chemistry, Bethesda, v. 153, p. 375380, 1944.

NOGUEIRA, A.; TEIXEIRA, S. H.; DEMIATE, I. M.; WOSIACKI, G. Influência do processamento no teor de minerais em sucos de maçãs. Ciência e Tecnologia de Alimentos, Campinas, v.27, n.2, p. 259-264, 2007.

OLIVEIRA, L. F.; NASCIMENTO, M. R. F.; BORGES, S. V.; RIBEIRO, P. C. N.; RUBACK, V. R. Aproveitamento alternativo da casca do maracujá-amarelo (Passiflora edulis F. Flavicarpa) para produção de doce em calda. Ciência e Tecnologia Alimentos, Campinas, v.22, n. 3, p. 259- 262, 2002.

ROCHA, A. A.; PEREIRA, D. N.; PADUA, H. B. Produtos de pesca e contaminantes químicos na água da Represa Billings, São Paulo (Brasil). Revista de Saúde Pública, São Paulo, v.19, n.5, p.401-410, 1985.

SHILS, M. E.; OLSON, J. A.; SHIKE, M.; ROSS, A. C. Tratado de nutrição moderna na saúde e na doença. 9.ed. São Paulo: Manole, 2003. v.1.

SOARES, M. R. Coeficiente de distribuição (KD) de metais pesados em solos do Estado de São Paulo. 2004. 202 f. Tese (Doutorado) - Escola Superior de Agricultura Luiz de Queiroz, Piracicaba, Piracicaba, 2004. 